3. Результаты исследований доказали возможность применения эффективных технологий утилизации тепловой энергии мощных воздушных турбокомпрессорных установок как без ТН, так и с ними. При этом разработанная автоматизированная методика показывает пути и перспективы автоматизации и компьютеризации управления подобными технологиями на практике.

\section{Библиографические ссылки}

1. Олишевский Г.С., Олишевский И.Г. Обоснование применения теплонасосного оборудования для теплофикационного режима конденсационных электростанций. Вісник Дніпропетровського університету. Серія: Ракетнокосмічна техніка. 2014. № 4. Т. 22. вип. 18(2). C. 135-140. URL: https://drive.google. com/file/d/1cW8-1RijvKdge-CZ3QAdPcXE$\underline{\mathrm{rASPxqV} / \text { view }}$ (дата звернення: 25.05.2018).
2. Олишевский Г.С., Олишевский И.Г. Обоснование применения теплонасосного оборудования для утилизации тепловых потерь в силовых трансформаторах большой мощности. Вісник Дніпропетровського університету. Серія: Ракетно-космічна техніка. 2015. № 4. Т. 23. Вип. 18(1). С. 131-136. URL: http://nbuv.gov.ua/UJRN/vdurkt 2015 23 18(1) 22 (дата звернення: 25.05.2018).

3. Олишевский И.Г. Обоснование рациональной схемы теплонасосной системы отопления. Механіка гіроскопічних систем. 2015. Вип. 30. С. 2635. URL: http://nbuv.gov.ua/UJRN/mgs 2015 305 (дата звернення: 25.05.2018).

4. Разумний Ю.Т., Заїка В.Т., Степаненко Ю.В. Енергозбереження : навч. посіб. Дніпропетровськ : Національний гірничий університет, 2005. $166 \mathrm{c}$.

\title{
УДК 621.454.2.046.4:662.75
}

\section{ИСПОЛЬЗОВАНИЕ ЧИСЛЕННОГО МОДЕЛИРОВАНИЯ ПРИ РАСЧЕТЕ ОСТАТКОВ КОМПОНЕНТОВ ТОПЛИВА}

\author{
И.Н. Орлянская, О.М. Иванов \\ Государственное предприятие «Конструкторское бюро «Южное» им. М.К. Янгеля», \\ ул. Криворожская, 3, г. Днепр, 49008, Украина, \\ e-mail: innaorlyanskaya@gmail.com,oleg-ivn@ukr.net
}

\begin{abstract}
Проведено порівняльний аналіз результатів визначення залишків компонентів у системі живлення двома методами: експериментальним та чисельним. Експериментально залишок визначали на масштабній моделі, чисельно - використовуючи програмний продукт ANSYS (CFX). Надано рекомендації щодо налаштування програмного продукту для отримання задовільної збіжності 3 експериментальними даними.

Ключові слова: забірний пристрій, система живлення, залишки компонентів палива, гідравлічний залишок, ANSYS, FluidFlow, CFX.
\end{abstract}

Analysis comparison of the results of the determination of the propellant residual in the propellant supply system by two methods: experimental and numerical was spent. Experimentally, the propellant residual was determined by the scale model. The propellant residual was determined numerically using ANSYS (CFX) software. Recommendations are given for setting up the software product to obtain satisfactory convergence with experimental data.

Keywords: intake device, propellant supply system, propellant residuals, hydraulic residual, ANSYS, Fluid Flow, CFX.

Проведен сравнительный анализ результатов определения остатка компонента в системе питания двумя методами: экспериментальным и численным. Экспериментально остаток определялся на масштабной модели, численно - используя программный продукт ANSYS (CFX). Даны рекомендации по настройке программного продукта для получения удовлетворительной сходимости с экспериментальными данными.

Ключевые слова: заборное устройство, система питания, остатки компонентов топлива, гидравлический остаток, ANSYS, FluidFlow, CFX. 
Введение. При проектировании ракет-носителей рассчитываются запасы топлива, необходимые для выполнения заданных миссий. В число этих запасов входят остатки компонентов топлива (ОКТ).

ОКТ представляют собой часть топлива, которая не может быть выработана из системы питания из-за нарушения требований к компонентам топлива, предъявляемых двигательной установкой (ДУ). К таким требованиям относят: обеспечение сплошности компонентов топлива, давления на входах в двигатели и других параметров в пределах, обеспечивающих работоспособность ДУ.

Традиционно при проектировании новых заборных устройств опираются на результаты, полученные при экспериментальной отработке ранее разработанных изделий. Эмпирические зависимости, полученные по результатам испытаний, справедливы для конкретной конструкции заборного устройства и узкого диапазона параметров $[1 ; 3 ;$ 7]. Их применение при проектировании нового изделия вынуждает использовать коэффициенты запаса, которые, в свою очередь, снижают массу выводимого полезного груза.

Использование численного моделирования средствами программного продукта ANSYS позволяет эффективно применять его при определении ОКТ на любых режимах работы двигателей, при различных условиях полета и при произвольной конфигурации трактов питания.

Постановка задачи. Целью исследования являлось применение численного моделирования в программном продукте ANSYS для решения задач по определению остатков топлива в системе питания.

Для подтверждения достоверности численного расчета результаты сравнивались с экспериментальными данными.

Для исключения влияния на результаты масштабного фактора и различий в свойствах компонента и модельной жидкости численный расчет проводился для условий, максимально приближенных к экспериментальной отработки, а именно: одинаковые масштабы моделей, ускорение свободного падения, модельная жидкость.

Задачами исследования являлись:

- определение гидравлического остатка в баке;

- определение гидравлического остатка в системе питания;

- построение зависимости остатка от критерия подобия Фруда;

- сравнение с экспериментальными данными.

Объект исследования. Объектом исследования являлась масштабная модель системы питания окислителем ДУ I ступени космической РН. Масштабная модель прошла наземную экспериментальную отработку, в результате которой получены зависимости гидравлического остатка в баке и в системе питания от критерия подобия Фруда.

Расчетные модели представляли собой трехмерные электронные модели тракта питания, имеющие те же основные геометрические характеристики, что и экспериментальные модели.

Для выполнения граничных условий к расчетным моделям подсоединялись прямолинейные участки трубопроводов длиной, равной десяти диаметрам трубопровода.

Расчетные модели представлены на рис. 1: a) - для определения остатка в баке; б) - для определения остатка в системе питания.

Для упрощения расчета при исследовании гидравлического остатка в системе питания ребра в расчетной модели не моделировались.

Методы и способы исследования. На заключительном этапе полета при сливе из бака образуется гидродинамический провал уровня над сливным отверстием. Прорыв газа в расходную магистраль происходит при достижении критического уровня топлива, высота которого определяется конструкцией заборного устройства и зависит от числа Фруда. По критическому уровню определяется гидравлический остаток в баке $[1 ; 4 ; 5]$. 


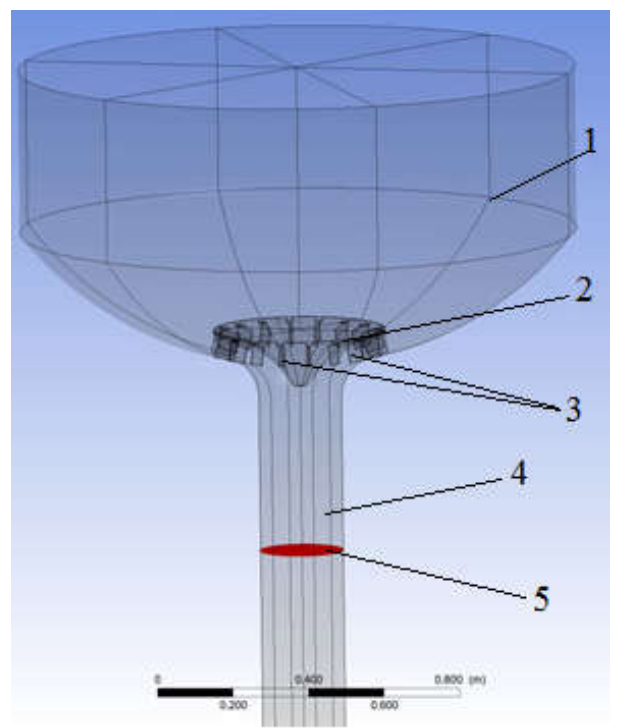

a)

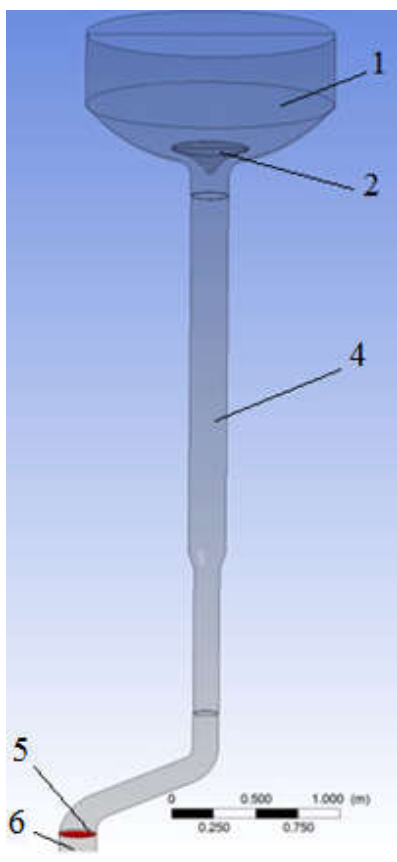

б)

Рис. 1. Модели для исследования гидравлического остатка:

1 - бак; 2 - заборное устройство; 3 - ребра; 4 - трубопровод; 5 - расчетное сечение;

6 - прямолинейный участок трубопровода для обеспечения граничных условий

После прохождения критического уровня происходит проникновение газа наддува под свободный уровень топлива в расходную магистраль и формирование газожидкостной смеси из-за взаимодействия свободной поверхности со струей, образованной стекающими остатками топлива с днища бака и заборного устройства. Газожидкостная смесь при постоянном расходе топлива перемещается вдоль тракта питания и попадает в двигатель.

Процессы движения газожидкостной смеси описываются системой нелинейных дифференциальных уравнений в частных производных - уравнениями Навье Стокса с учетом каждой фазы, которые в общем случае включают в себя: уравнения неразрывности, движения, энергии и диффузии [6].

При использовании программного продукта ANSYS с модулем Fluid Flow (CFX) исходные дифференциальные уравнения в частных производных заменяются системой алгебраических уравнений, которые при использовании метода конечных объемов связывают между собой значения искомых переменных в группе узловых точек. Конечно-элементная сетка с узловыми точками, построенная при численном моделировании, распределяется по всей вычислительной области во времени и в пространстве [2].

Для расчетов в ANSYS (CFX) была выбрана Эйлерова модель VOF (Volume of Fluid), которая используется для моделирования многофазного течения с четкими границами раздела фаз при опорожнении емкостей, плескании жидкости и движения больших пузырей газа в жидкости.

При выбранной модели VOF для каждой фазы решается один единый набор уравнений сохранения импульса и добавляются уравнения переноса объемной доли каждой фазы.

Исходя из граничных условий, в результате решения уравнений получают распределение параметров течения (скоростей, давлений, температур) в зависимости от пространственного расположения, определяющегося координатами $x, y, z$, и времени $t$. Нахождение параметров жидкости происходит итерационным методом.

Численные расчеты для определения остатков топлива проводились для следующих условий и режимов: 
- модельная жидкость: вода при температуре $11^{\circ} \mathrm{C}$;

- модель без переноса тепла;

- учет земной гравитации;

- расходы модельной жидкости: 44; 50; 75; 104; 119 дм ${ }^{3} / \mathrm{c}$;

- модель турбулентности: k-Epsilon $\left(\mathrm{Re}_{\text {вых. }}=2 \cdot 10^{5} \ldots 5 \cdot 10^{5}\right)$;

- граничные условия: на входе в модель - статическое давление, равное атмосферному, на выходе скорость, осредненная по сечению.

Результатом численного расчета было определение гидравлического остатка в момент, когда сплошность потока достигала заданного значения.

В процессе расчета газожидкостная смесь представляла собой столб, в котором сплошность жидкости менялась от 1 в нижней точке расчетной области до 0 на свободной поверхности. Условием определения гидравлического остатка по сплошности для расчетного сечения являлось:

$$
0,91 \leq \varphi \leq 0,99 ;
$$

где $\varphi-$ сплошность потока в расчетном сечении.

Сплошность потока контролировалась в расчетных сечениях, показанных на рис. 1. Расположение расчетных сечений соответствовало установке

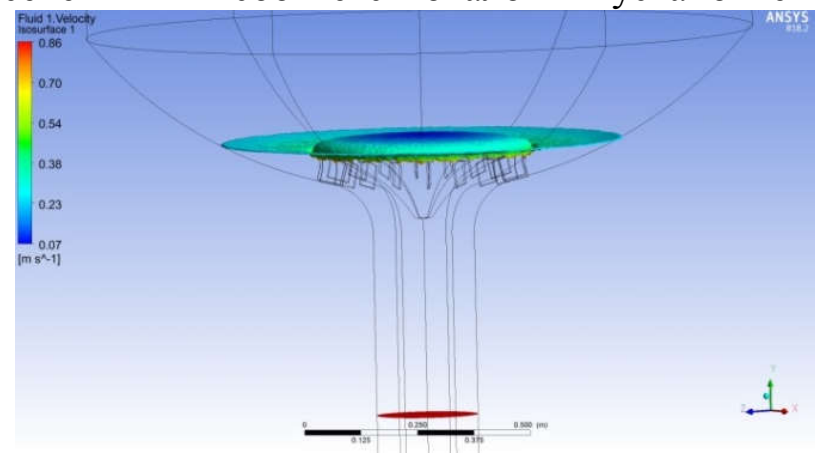

a)

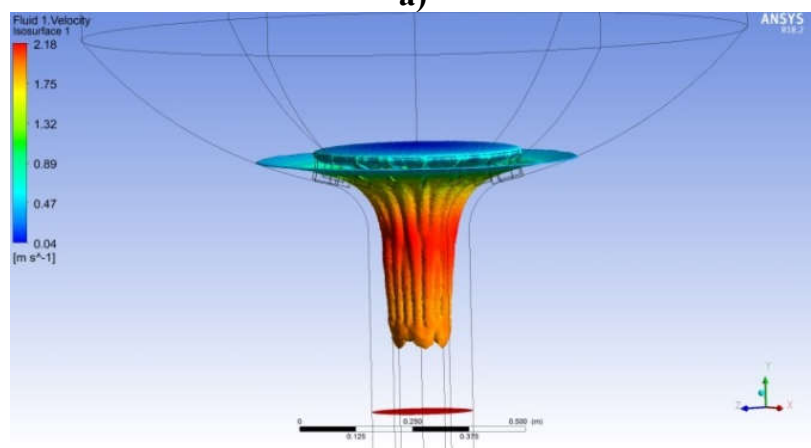

в) датчиков сплошности, по которым определялся гидравлический остаток в экспериментальных работах.

В момент времени, когда сплошность потока достигала значения, попадающего в диапазон (1), расчет останавливался и определялся гидравлический остаток по зависимости:

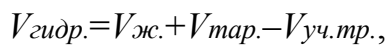

где $V_{ж \text {. }}$ - объем жидкости в модели на момент достижения сплошностью заданного значения;

$$
\begin{aligned}
& V_{\text {map. }} \text { - объем жидкости в тарели; } \\
& V_{\text {уч.mp. }}-\text { объем прямолинейного }
\end{aligned}
$$
участка трубопровода, подсоединенного для обеспечения граничных условий.

Результаты. Результаты численных расчетов представлены на рис. 2-5.

На рис. 2 а) - г) показана граница раздела жидкой и газовой фазы при сливе из бака, на рис. 3 а) - в) - при сливе из системы питания.

На рис. 2 а) - в) виден гидродинамический провал уровня над сливным отверстием. На рис. 3 показаны фазы движения газодинамической смеси по расходной магистрали. По мере продвижения вдоль магистрали газовая фаза дробится на более мелкие пузыри.

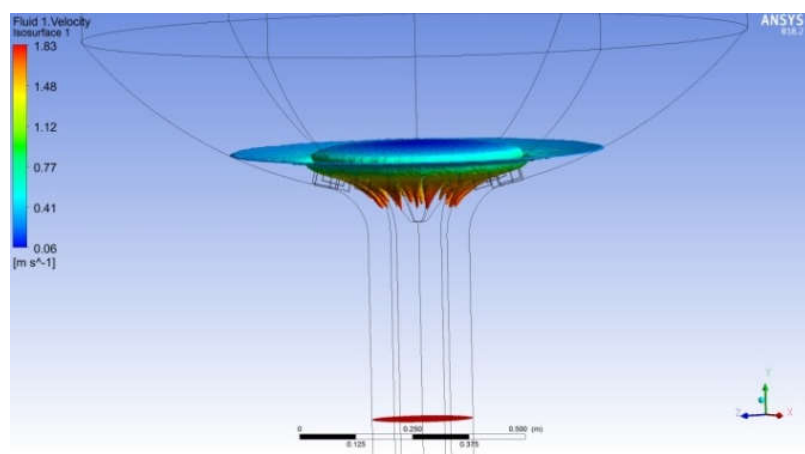

б)

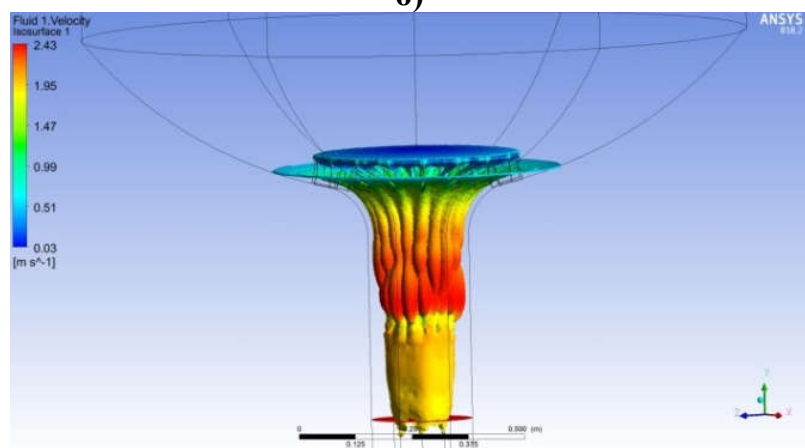

г)

Рис. 2. Динамика изоповерхности разделения газовой и жидкой фазы при сливе из бака 


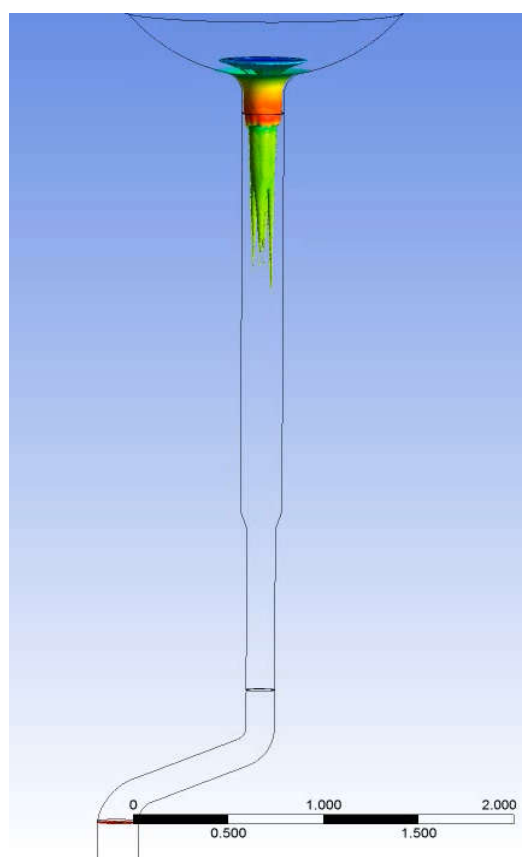

a)

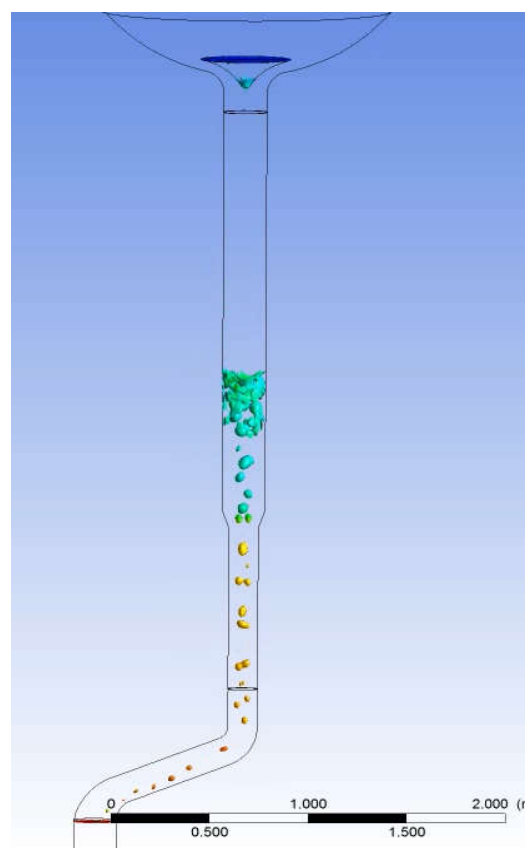

б)

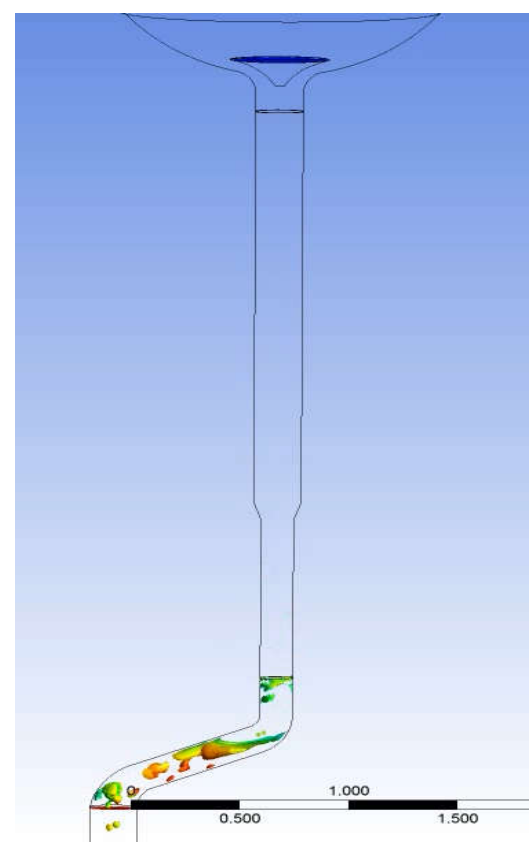

В)

Рис. 3. Динамика изоповерхности разделения газовой и жидкой фазы при сливе из системы питания

Рис. 2 г) и рис. 3 в) соответствуют моменту выполнения условия по сплошности (1).

На рис. 4 и 5 представлены результаты численных расчетов и экспериментальных работ.

На каждом режиме определялся

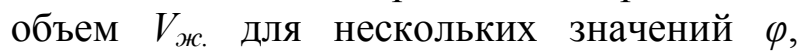
попадающих в заданный интервал, затем данные аппроксимировались степенной функцией:

$$
V \bar{\sigma}=474 \cdot \mathrm{Fr}^{0,34} \text {, }
$$
в баке.
Анализ полученных результатов. Как видно из рис. 4, численные расчеты имеют удовлетворительную сходимость с экспериментальными данными. Сходимость результатов расчета гидравлического остатка в баке зависит от числа Фруда: при малых расходах отличие расчета от эксперимента составляет $26 \%$, при максимальных расходах - до $4 \%$.

Разброс расчетных значений остатка можно объяснить тем, что не проводилось моделирование слива из тарели, а к вычисленному объему прибавлялся объем жидкости, заполняющей всю тарель.

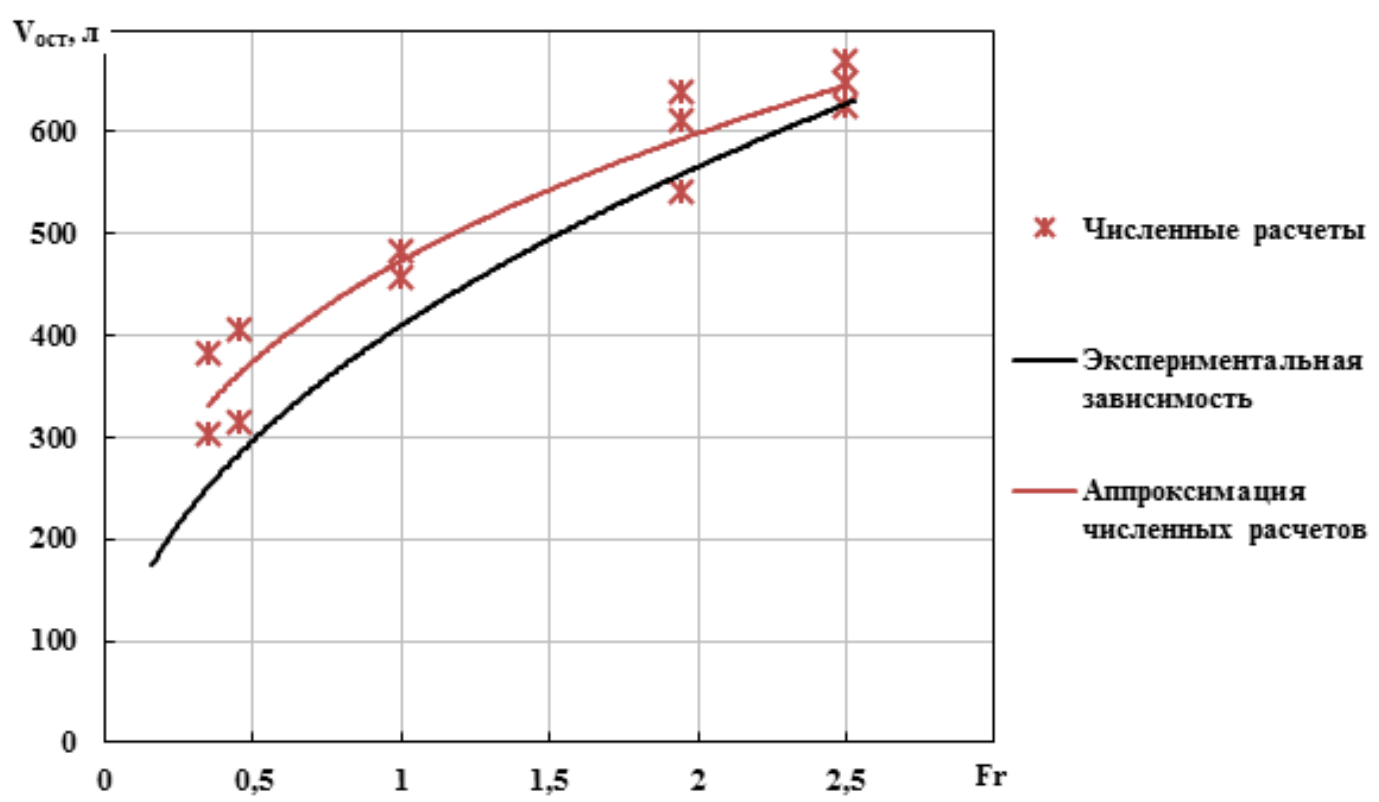

Рис. 4. График зависимости гидравлического остатка в баке от числа Фруда 


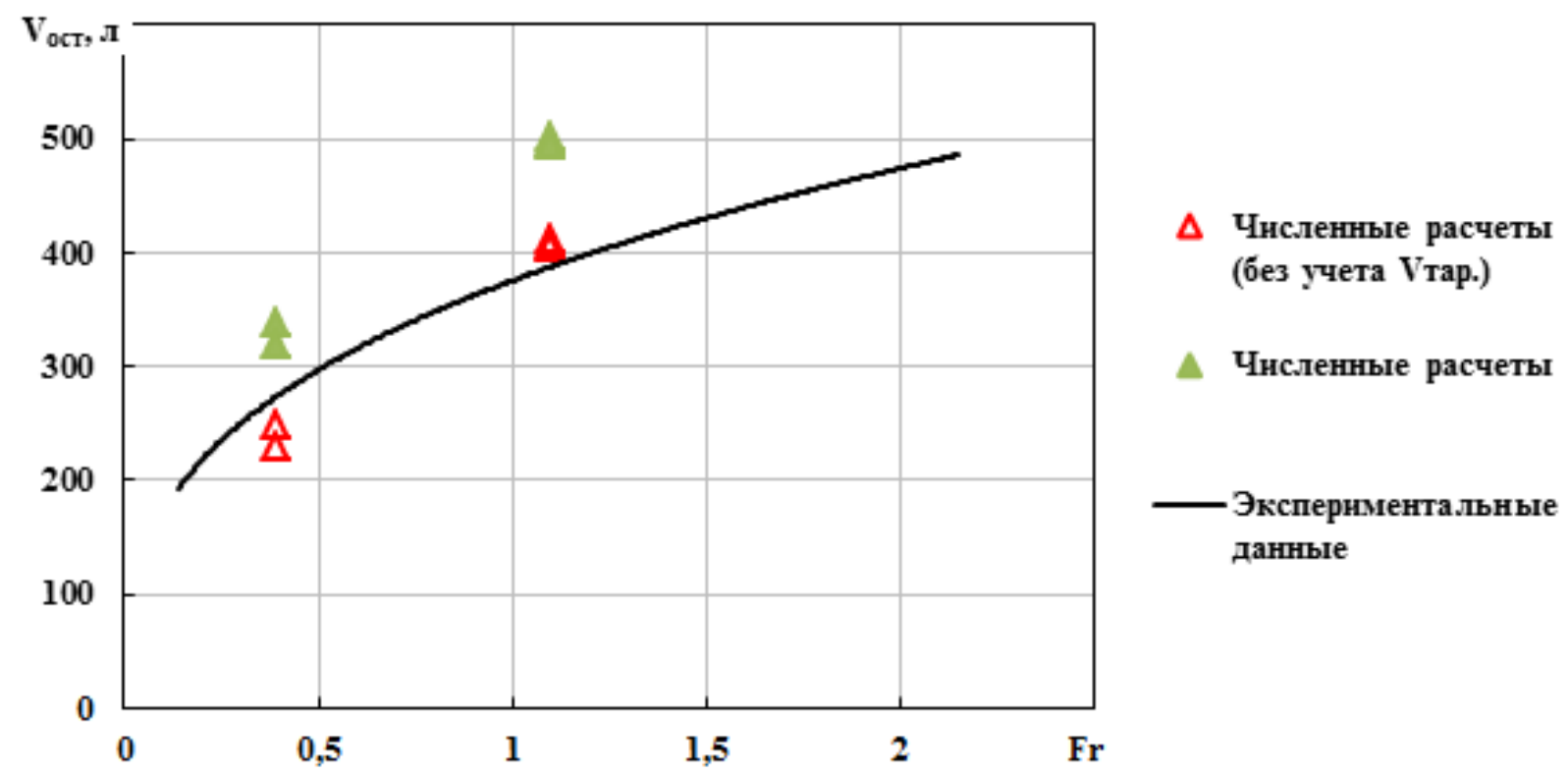

Рис. 5. График зависимости гидравлического остатка в системе питания от числа Фруда

При малых расходах жидкость из тарели полностью сливается и является составляющей гидравлического остатка. При больших расходах жидкость из тарели не успевает полностью слиться. Таким образом, прибавляя весь объем тарели к объему жидкости при малых расходах, значение остатка завышается на величину объема тарели. Отличие между расчетными и экспериментальными данными практически равно объему тарели, что подтверждает сделанное выше предположение.

К моменту формирования остатка в системе питания модельная жидкость полностью успевает слиться из тарели, поэтому на рис. 5 приведены результаты расчета с учетом объема жидкости в тарели и без его учета. Как видно на рис. 5, остаток без учета объема тарели имеет лучшую сходимость с экспериментальными данными.

Выводы. Использование численного моделирования при расчете остатков компонентов топлива в баках систем питания РН средствами программного продукта ANSYS (CFX) позволяет получить удовлетворительную сходимость с результатами эксперимента и может применяться на этапе эскизного проектирования для вновь разрабатываемых изделий.

\section{Библиографические ссылки}

1. Беляев Н.М. Системы наддува топливных баков ракет. Москва : Машиностроение, 1976. 336 с.
2. Бруяка В.А., Фокин В.Г., Солдусова Е.А., Глазунова Н.А., Адеянов И.Е. Инженерный анализ в ANSYS Workbench : учеб. пособ. Самара: Самар. гос. техн. ун-т, 2010. 271 с.: ил.

3. Давыдов С.А., Горелова К.В. Исследования проникновения газа в сливную магистраль на заключительном этапе опорожнения топливного бака. Космическая техника. Ракетное вооружение: науч.техн. сб. / под гл. ред. канд. техн. наук А.В Дегтярева; под науч. ред. канд. техн. Наук А.В. Новикова. Государственное предприятие «Конструк-торское бюро «Южное» им. М.К. Янгеля», 2012. Вып. 1. С. 228-234.

4. Поликовский В.И., Перельман Р.Г. Воронкообразование в жидкости с открытой поверхностью. Москва : Госэнергоиздата, 1959. $191 \mathrm{c.}$

5. Токарев В. Е. Истечение жидкости из емкости с образованием воронки. Известия высших учебных заведений. Сер. Авиационная техника. 1967. № 3. С. 92-94.

6. Флетчер. К. Вычислительные методы в динамике жидкостей. В 2-х т. Т. 1; пер. с англ. Москва : Мир, 1991. 504 с.: ил.

7. Шевченко Б.А. Расчетный и экспериментальный метод разработки средств забора компонентов из баков летательных аппаратов с жидкостным ракетным двигателем : дис. канд. техн. наук. Днепропетровск, 1990. 209 с.

Надійшла до редколегії 01.08.2018 p. 